\title{
Analysis on the Development of Tokyo Rail Transit and Its Enlightenment to Chengdu
}

\author{
Mengdi Bian \\ College of Urban Planning and Architecture, Southwest Minzu University, Chengdu, China \\ Email: 1073657369@qq.com
}

How to cite this paper: Bian, M.D. (2021) Analysis on the Development of Tokyo Rail Transit and Its Enlightenment to Chengdu. Open Access Library Journal, 8: e7631. https://doi.org/10.4236/oalib.1107631

Received: June 10, 2021

Accepted: July 6, 2021

Published: July 9, 2021

Copyright $\odot 2021$ by author(s) and Open Access Library Inc.

This work is licensed under the Creative Commons Attribution International License (CC BY 4.0).

http://creativecommons.org/licenses/by/4.0/

\section{(c) (i) Open Access}

\begin{abstract}
With the introduction of the intensive urban development model, urban rail transit, as a rapidly developing inter-city spatial association network, has become increasingly prominent in promoting social and economic development and has an important influence on the shaping of regional spatial structure. Taking the practical experience of Japan's rail transit development as an example, this article first combs its development history and summarizes the three organizational characteristics of its development model: diversified business entities, TOD model, and efficient use of underground space. On this basis, it summarizes Japan's success. Experience and design techniques for the utilization of underground space, and put forward several optimized development suggestions based on the current status and problems of the development of urban rail transit hub in Chengdu, providing reference and reference for building a multi-mode, multi-level, and coordinated regional integrated rail transit system For reference, in order to better play the supporting role of rail transit network on the development and growth of urban agglomerations in our country.
\end{abstract}

\section{Subject Areas}

Urban Planning

\section{Keywords}

Rail Transit Development, Station-City Integration, TOD Model, Underground Space

\section{Introduction}

China is currently in the stage of new urbanization. Faced with a series of urban diseases such as the deterioration of resources and the environment, social 
problems, and prominent contradictions, urban policymakers and planners have begun to propose intensive and compact urban development models. The pattern of urban built-up areas is basically under the background of limited growth of formation and construction land, urban rail transit will inevitably become the main way for the healthy development of the city and the optimization of the urban spatial layout. Research on rail transit networks at home and abroad mainly focuses on network structure and form, accessibility, vulnerability, line network planning, etc.; most research on rail transit in Japan focuses on stationcity integration, operation mode, and site complex In a single aspect such as the organizational model, there is less analysis of the internal space utilization of the site under the analysis of its orbital development model. In view of the abovementioned research status, this article summarizes the three main organizational characteristics of the rail transit network structure: the diversification of the rail transit network structure, the TOD model, and the utilization of underground space, based on the analysis of the history and mode of the development of rail transit in Japan. The design method of space utilization and finally put forward several optimization development suggestions based on the status quo of Chengdu's rail transit, hoping to provide reference and reference for Chengdu to build a multi-mode, multi-level, and coordinated regional integrated rail transit system.

\section{Overview of Tokyo Rail Transit Development Mode}

\subsection{Brief Description of the Development History of Tokyo Rail Transit}

Before 1897, it was the early stage of the development of Tokyo's rail transit, and Tokyo began its first trial of rail transit lines. In 1872, a railway line was opened from Shimbashi to Yokohama, and a carriage railway was opened in 1882 [1].

The period from 1900 to 1920 was the growth stage of the development of Tokyo rail transit. Tokyo's urban rail transit network began to gradually extend from the single center, and expand to the surroundings with the Yamanote line as the center. In 1900, the divergent rail network strengthened the connection between the city center and the surrounding areas, and the rapid spread of trams, this progress more effectively promoted the rapid development of Tokyo rail transit. In 1919, a small intercity rail transit network with Tokyo Station as the core and gradually extended outwards was formed [1].

The period from 1921 to 1950 was the forming stage of Tokyo's urban rail transit network. In 1925, Tokyo built the eastern section of the Yamanote Loop Line, forming a "ring" national railway network. With the Yamanote Line as the core, the development of the city continues to extend to suburbanization along the track. Tokyo's first subway line, the Ginza Line, was opened in 1927, with a length of $14.2 \mathrm{~km}$. In 1939, the subway line from Shibuya to Shimbashi on the Ginza Line was connected to strengthen the connection and exchange between the lines [1]. 
After 1955, Tokyo rail transit was gradually mature. Tokyo's economy began to develop, and the city continued to expand to the surrounding areas. The Tokyo government realized the problem of urban structure and began to make necessary adjustments to the urban pattern of Tokyo City. Through the use of rail lines, part of the functions of Tokyo's central area was transferred, and the urban structure was transformed from a single center to a multi-center. So Tokyo began to build radiation from the Yamanote Line to guide the development of new surrounding cities. At the same time, Tokyo has also strengthened the comprehensive development and utilization of surrounding land due to the large passenger flow of the Yamanote Line, introducing a large number of commercial and supporting service facilities, promoting the gathering of people, and finally forming seven sub-city centers and five Tama areas The polycentric urban structure of a nuclear city.

With the increase in the demand for rapid inter-city transportation and the further improvement of passengers' requirements for travel efficiency, Japan has further improved the Shinkansen rail network nationwide. As of March 2019, the total operating mileage of the Shinkansen reached $3041 \mathrm{~km}$.

\subsection{Tokyo Rail Transit Development Model}

\subsubsection{Diversification of Tokyo Rail Transit Operators}

What is quite different from the development of China's rail transit is that Tokyo's rail transit operators are diversified, and are divided into state-owned and privately-owned ones. Tokyo's rail transit was innovated and developed by a personal railway company. The state-owned and private rail routes are connected and mutually convenient, so that the transfer connection is orderly, which facilitates the barrier-free between suburban citizens and passengers in the city center. Exchanges have also increased passenger flow.

Japanese rail transit can be divided into "JR", "Shinkansen", "Private Railway", "Subway", and "Others". Tokyo mainly has subway, JR railway and private railway. Different lines are operated by different entities. Responsible for construction and operation, JR is the former state-owned railway. After the reform, it was taken over by a different company. It was divided into JR Hokkaido, JR East, JR Tokai, JR West, JR Shikoku, JR Kyushu, and JR freight; Shinkansen: Japan's high-speed rail; Private railways are railways built by private companies. There are companies such as Tokyu, Keikyu, and Keisei; subways, commonly known as subways, have the largest scale and utilization rate in the three cities of Tokyo, Osaka, and Nagoya.

\subsubsection{The Tokyo Rail Network Is Dense and Covers a Wide Range}

Tokyo's rail transit covers a wide area, like a dense network of lines running through the ground and underground. Two loop lines and more than 20 launch lines are intertwined and staggered. At the same time, they connect the tracks of the city center with the suburbs and surrounding counties. Tokyo's underground transportation network is the most advanced in the world, and it is formed by 
connecting more than 50 lines of subways and trams to each other. Among them, the Shinkansen has densely distributed lines and reasonable layout. As the longest completed Yamanote Line, it undertakes most of the commuters in the center of Tokyo. It runs in the center of Tokyo in a loop. The total length of the route can reach $34.5 \mathrm{~km}$ and there are 29 stations [1]. Tokyo's ground transportation network is composed of expressways and roads for general vehicles, mainly expressways. It consists of an outer ring line, a central area ring line, a city center ring line and a divergent line connecting the suburbs and counties. The lines are interlocked and can accommodate the distribution and commuting of more than 40 million people in the Tokyo metropolitan area. The transportation links are close, and at the same time, it effectively promotes the economic exchanges between various regions, and generally improves the economic development level of the entire city. The density of the average rail transit network in Tokyo far exceeds that of some developed cities in the world, such as Paris, London, etc., with an average of $300 \mathrm{~m} / \mathrm{km}$, and the density of the rail network in the city center is even as high as $1010 \mathrm{~m} / \mathrm{km}^{2}$.

\subsubsection{TOD Mode of Tokyo Rail Transit}

TOD (Transit-Oriented-Development) model is a development model that uses public transportation to drive urban development. Through the development of public transportation, especially the use of rail transportation to connect the city with the main surrounding towns and economic activity centers, intensive development is carried out at the station and along the line, and the residential, work, and commercial centers are concentrated near the station, thereby guiding people to more Use public transportation and reduce the use of private cars.

The TOD model realizes the mutual linkage mechanism between urban land construction and rail transit, and cleverly converts the public welfare nature initiated by the state into commercial nature, guides real estate to participate in investment and development, explores commercial business models, and then gradually improves urban supporting infrastructure and optimizes regions The functionality of the land, enhances the value of regional land, and the valueadded of land also brings positive feedback to the city, forming a continuous and effective virtuous construction cycle. Rail transit can guide the reasonable distribution of population and create a large-scale network node-type city and urban agglomeration structure [2].

Japan's first TOD complex project is Shibuya Mark City, which is also Tokyu's first depot superstructure complex. In the development of the complex, the Ginza Line vehicle inspection base, the Tokyu bus dedicated road, and the upper space of the Shibuya Station site on the Keio Inou Line are flexibly used to connect offices, hotels, entertainment facilities, railway stations, subway stations, etc. A new vibrant space in Shibuya City, Later, with the transformation and upgrading of urban industries to service industries, and the emergence of large numbers of urban white-collar workers, people's requirements for the completeness of public service facilities and the diversity of cultural life have in- 
creased. More and more TOD projects have escaped from the traditional highdensity, Highly mixed architectural forms tend to be more refined and heterogeneous.

\subsubsection{Utilization of Tokyo Rail Transit Underground Space}

Underground space is a part of three-dimensional space. Fully developing and utilizing underground space will solve the problem of shortage of urban resources and also enrich the spatial form of the city. As an island country with extremely scarce land resources, Japan cannot expand its land horizontally. In order to better improve the utilization rate of land, the development and use of underground space have become an inevitable and effective way. The underground space can be regarded as the continuation and supplement of the ground space in the vertical direction, and unified and reasonable planning is required. In order to ensure the orderly and efficient operation of the various functions of the city, Japan has begun to explore the development of urban underground space as early as 1930. Compared with other large cities in the world, Tokyo's orbital underground space is a successful practical case. The underground development in Tokyo can go as deep as $100 \mathrm{~m}$ underground. Generally, the first 1 - 4 floors below the ground are used as public activity spaces, and the underground 5 - 7 floors are arranged as underground transportation spaces [1]. The underground transportation network, underground commercial streets, underground passages and underground parking lots are connected to each other, forming a new type of underground space unit with subway stations as the core node, combining transportation and commerce, and these units are connected through the subway network. Up, residents can complete multiple activities such as commuting, shopping and leisure underground. Good spatial communication between underground and above ground can relieve the traffic pressure on the ground near the traffic station, and at the same time enrich the spatial landscape on the ground, making the city underground, The resources on the ground and on the ground are fully utilized, forming a good cycle of environmental and economic win-win.

For example, Tokyo Railway Station, which integrates multiple modes of transportation such as railways, intercity rails, and subways, mainly includes three lines and stations in the underground part. One is the JR Sobu Line, Yokosuka Line, and the Yokosuka Line on the fourth and fifth floors. The station (the fourth floor is the hall floor, and the fifth floor is the platform floor); the second is the JR Keiyo Line and the station located on the third and fourth floors underground (the third floor is the hall floor, and the fourth floor is the platform floor); The third is the Tokyo Metro Marunouchi Line and station located on the second underground floor. The three underground stations are connected to each other through a connecting passage on the first basement level, which connects the Marunouchi underground station, the Yaesu side station building and the underground shopping street at the same time. The Yaesu-side station is a building with 12 floors above ground and two floors underground. The first and 
underground floors are used for station facilities and underground shopping streets (Tokyo Station No. 1 Street). The second floor and above are Daimaru Department Store. The underground mall connects the entire underground space with Tokyo Railway Station and the surrounding 16 buildings. The traffic space and the commercial space complement each other with complete functions, which improve the double utilization of the above-ground and underground space [3].

\section{Tokyo Underground Rail Transit Space Case and Design Analysis}

\subsection{Shibuya Station}

Shibuya Station is one of the important hubs of Tokyo's rail transit. The rail transit is very developed, with many traffic lines running through it. Shibuya Station is also a transportation and commercial complex integrating hotel, office, commerce, transportation, parking and other functions. Above Shibuya Station stands the Shibuya Light, Blue Tower Building, ShibuyaMark City, 109 and other Tokyu buildings called the city's name card.

The pedestrian system at Shibuya Station is not limited to the plane level, but the pedestrian route planning at the elevation level is even better. Because the topography of Shibuya valley leads to different heights, the designer combined the topography to establish a four-story space walking system from underground to above ground, connecting subway stations, ground, corridors, sky corridors, and "urban core" buildings. Create a coherent and innovative walking network. On the nodes of the pedestrian network, a variety of forms, rich rest plaza spaces and distinctive portal plazas, as well as connecting facilities such as corridors and platforms, are set up so that people can pass through the stations and areas with different functions (Figure 1).

The entire three-dimensional system of Shibuya Station is connected in series by the "urban core" elevator system. Considering the large passenger flow, the overall design space of the station is very sufficient, but there are related facilities on each floor to guide walking, making the hierarchical space full of travel. In Shibuya Station, there is an underground bicycle parking lot above the train station of the Fukutoshin Line, and there is a public parking lot below the underground taxi station at the West Exit. There are also many bicycle parking stations and rental points around Shibuya Station to facilitate people's travel.

"Shibuya Light" is one of the five major renewal projects in Shibuya District, and it is called the "three-dimensional city" on the rail line. The underground space of Shibuya Lights and the ground are vertically connected by the "urban core" that integrates the underground and above-ground spaces. The B5-B3 floors are the subway station, the B3-7 floors are commercial facilities that seamlessly connect with the subway station, the $11-16$ floors are the grand theater that can accommodate about 2000 people, and the 17 - 34 floors are the office buildings. 


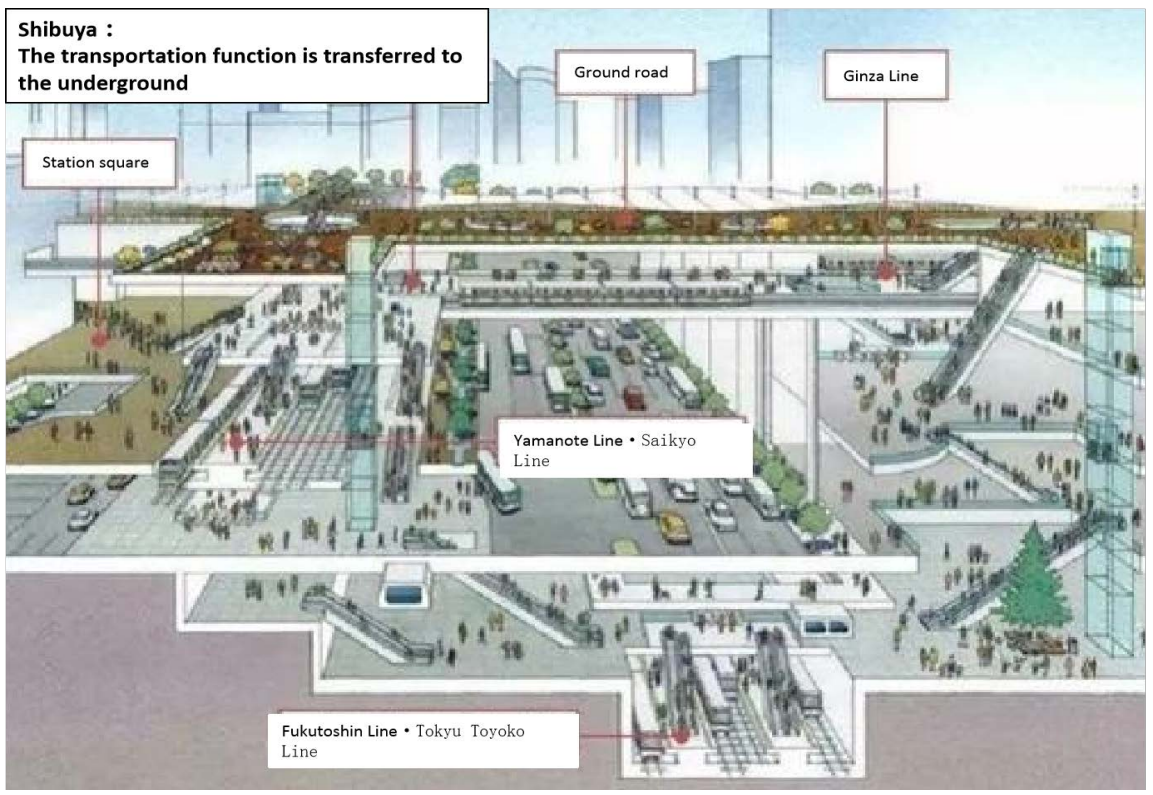

Figure 1. Shibuya station traffic stereoscopic system (Source: Internet).

The most worth mentioning is that the "city core" in Shibuya Light adopts the natural ventilation and energy-saving system of train wind. This vertical through space can be used to complete the natural ventilation of the subway. The running of the train will generate heat and wind, and the high-temperature air will flow from the station. Ascend, it will generate updraft, which will flow into the sky, causing the pressure in the station to drop. At this time, fresh air on the ground will flow into the underground space along the pressure difference, forming natural convection, completing automatic ventilation, and achieving energy conservation and environmental protection (Figure 2).

\subsection{Summary of Design Methods for Underground Space of Rail Transit}

Tokyo is a city that has successfully practiced underground space for rail transit. During the construction process, the development of underground space is not only as a transportation space, but also through specific design techniques to ingeniously introduce citizen's activity space into the underground. The following is through the use of Tokyo subway stations, etc. The key points of underground space design collected and sorted out by underground space cases:

\subsubsection{Spatial Scale Design}

The sense of scale of space is a key element that determines whether the space is transparent. Different spatial scales will make people have completely different psychological feelings. An open space will make people comfortable and pleasant, and a suitable space will give people peace of mind, natural and narrow. The space can be depressing and uneasy. As the only subject of space activities, human beings are very important to the design of humanized space scales, and it is also a decisive factor to determine whether a space can continue to exist. 


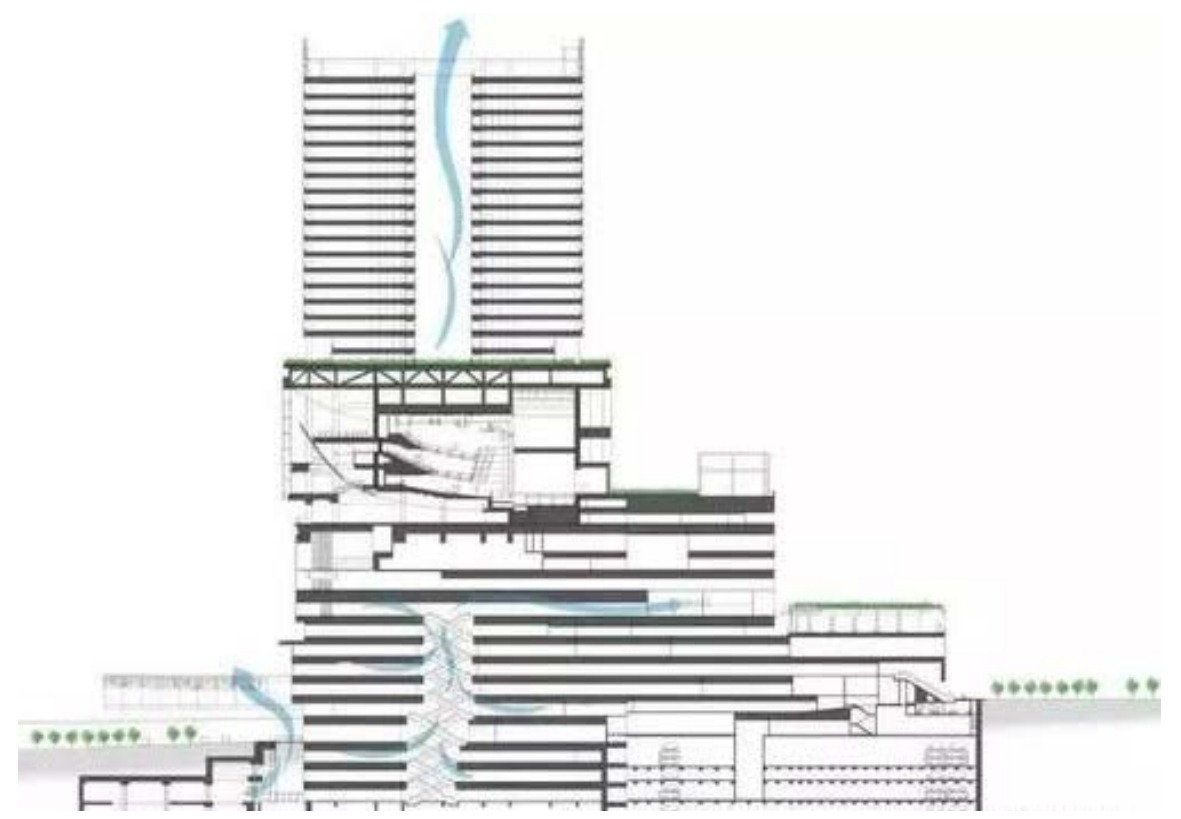

Figure 2. Shibuya station ventilation system. Shibuya Light (Source: Internet).

\section{1) Creation of open space}

Because of people's inherent cognition of the narrow and dark underground space, creating open and transparent public space in underground space has become the primary method to solve the problem. Due to the activity characteristics of public space, its architectural scale cannot be smaller than that of ordinary living space, and the open space in the underground space should be expanded as much as possible on a controllable basis. The open space is very inclusive, and people are relatively free and happy to move in the open space. At the same time, the open public space facilitates the introduction of external elements and better connects with the ground space system.

2) The choice of interior decoration materials

The permeability of the space can also be expressed through the creation of the space atmosphere. The interior decoration materials of the space can guide people's visual effects to a certain extent and affect people's psychological feelings. In the selection of materials in the underground space, try to choose lightertextured decorative materials, such as light wood, light-colored marble, paint, etc. The selection of light-textured materials will give people a fresh and comfortable space feeling psychologically, and avoid creating depression Heavy space atmosphere. Secondly, the use of internal decoration materials is also exquisite. Linear decoration will drive people's vision to extend in the direction of the lines, which will broaden the field of vision. Some rhythmic elements can also be added to the space to increase the overall rhythm of the underground space, sense and agility.

3) The use of color

Color, material, and spatial scale can form a complementary relationship. The use of colors can be combined with space materials to create a rich space at- 
mosphere and express different space themes. When the scale of the underground interior space is too limited, colors with higher brightness can be selected. By increasing the brightness of the space, the visual effect of magnifying the scale of the space can also be achieved. On the contrary, if the underground space is too empty, a relatively darker color can also be selected. It can buffer the visual effect.

\subsubsection{Ventilation System Design}

1) Cleverly design the wind path to guide the flow of natural wind

The ventilation of underground space is usually divided into artificial ventilation and natural ventilation. Under the condition of meeting the necessary artificial ventilation, with the concept of energy saving and environmental protection, the air path is designed through reasonable and ingenious design to guide the flow of natural wind to achieve green ventilation. The effect of improving air quality, for example, the "city core" in Shibuya Light adopts a natural ventilation and energy-saving system of train air ventilation. The heat generated by the train travels and forms a certain gap with the surrounding air pressure, forming the most natural fresh air system.

2) Reasonably arrange the fresh air system

The fresh air system is the main means to improve the quality of the underground space, and air inlets and outlets of different sizes can be arranged according to the scale of the space. Install large-size air inlets and outlets in areas with crowded people, and small-size air inlets and outlets in areas with relatively evacuated people and good air flow. In the layout of the fresh air system, the distance between the inlet and outlet should not be too close. Too close will cause the outside fresh air to be exhausted without fully reaching the room. The pipelines of the fresh air system should be shortened as much as possible, branch pipelines should be reduced, and complicated local components should be avoided to save materials and reduce local wind resistance.

3) Properly introduce natural elements to purify the air

Water bodies can be used to improve air quality. A large amount of water bodies can absorb fine dust in the air, thereby purifying the air and benefiting people's health. For example, Nagoya Central Park in Japan facilitates water bodies to improve air quality. Plants can also be used to purify the air. Plants can absorb carbon dioxide produced by people and release pure oxygen for people to use. Green plants are often one of our ways to improve air quality. Introducing plant elements in the right space can not only improve the air quality, but also enrich the sense of hierarchy of the space environment.

\subsubsection{Light Environment Design}

1) Light through skylights or patios

Through the design of skylights and sunken square space, natural light and natural air are introduced into the underground space. Now this method is commonly used in the design and transformation of underground space. The 
introduction of natural light can also be used as one of the ways to introduce the elements of the external environment, which can eliminate people's sense of depression in the underground space to a certain extent [4]. Such as the Nikkei Kyoto New Subway Station (Figure 3), the Nagahori Underground Street (Figure 4), etc. About one-third of the space in the Nagahori Underground Street is designed with skylights to reflect natural light. 8 skylights are opened on the top surface of the public underground walkway, which are connected to each other in a wave shape, so that the internal space is full of light. At the same time, it increases the agility of the space and forms a unique landscape on the ground.

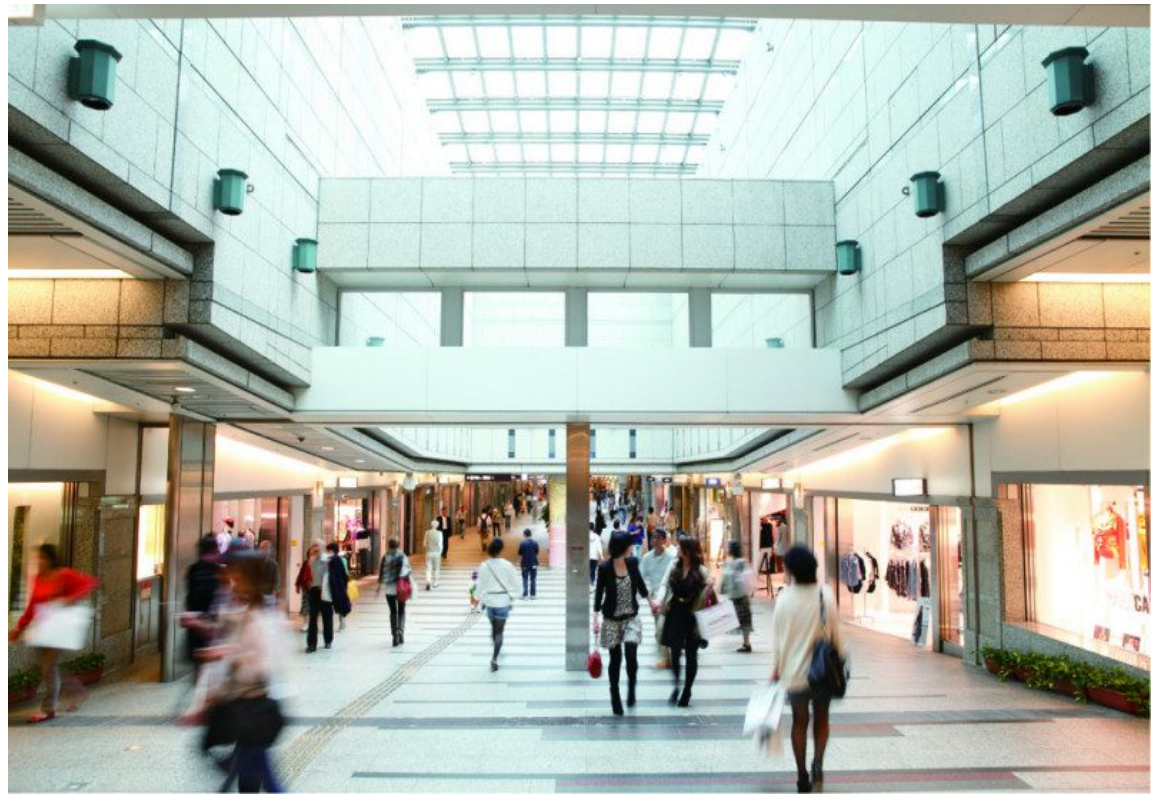

Figure 3. Nagahori, Osaka, Japan (Source: Internet).

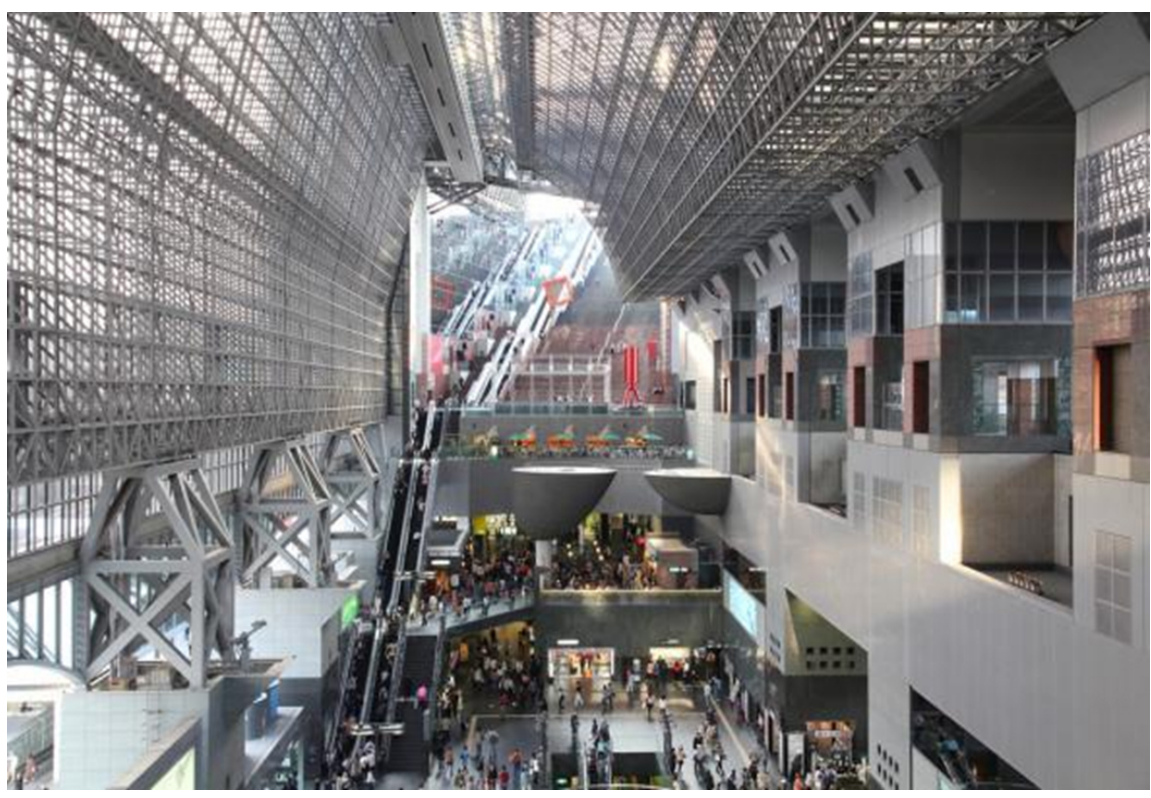

Figure 4. Hiki Kyoto new subway station (Source: Internet). 
2) Reasonable placement of artificial lighting equipment

Although natural light will be introduced into the underground space, natural light is not enough to bear the lighting role of the space in large spaces, and the reasonable placement of artificial lighting is also very important. Artificial lighting in underground space also needs to be controlled, not as many as possible. Due to conditions, the illuminance standard of underground space is higher than that of ground buildings of the same scale and type. Under proper lighting conditions, artificial lighting equipment should be arranged reasonably to avoid areas that are too concentrated or too scattered, resulting in excessive lighting and weak light (Figure 5). In order to achieve energy saving and environmental protection, intelligently adjusted artificial lighting equipment can be used, and different illuminances can be adjusted according to different functions. For example, the illuminance can be appropriately reduced at the entrance of the subway, and the design of the entrance usually introduces natural light; in the rush hour, the illuminance can be intelligently increased and so on [4].

3) Light pipe lighting system

The principle of the light pipe daylighting system is to capture and collect sunlight by placing it with outdoor daylighting equipment, and then introduce it into the system, and then transmit it through the high-tech light pipe, even long distances or corners for transmission, and finally pass through The diffuser material at the bottom irradiates the light without ultraviolet rays evenly into the underground space [4].

\subsubsection{Clear Guidance System Design}

Because of the limited conditions of the underground space, the line of sight is usually blurred. People need a clear and conspicuous traffic guidance system and adequate lighting conditions during the transfer. Nowadays, under the background of the developed and complex rail transit network and people's time cherishing, people increasingly emphasize the rapid identification of the traffic guidance system. Japanese design has always paid attention to humanization, and the sign and logo of public space can be quickly and accurately recognized by people in the meaning of their expressions, which is worthy of learning and reference.

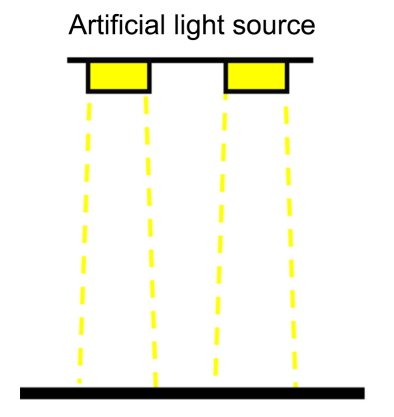

1) Insufficient lighting

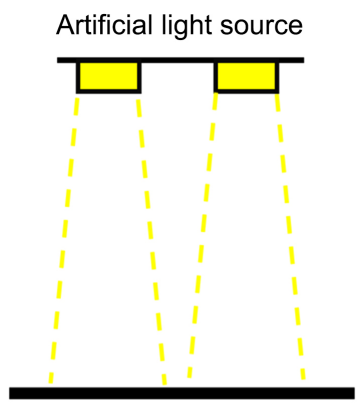

2) Suitable lighting

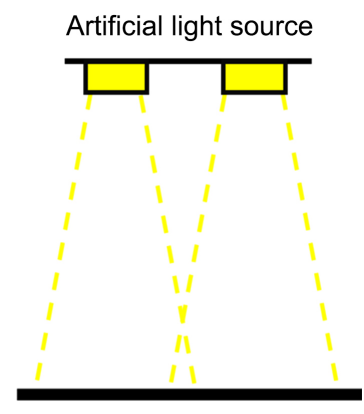

3) Excessive lighting

Figure 5. Source: (redrawn based on reference [4]). 


\subsubsection{Fire Protection Design of Underground Traffic Space}

Regarding the fire protection layout of underground space, under reasonable circumstances, try to make the layout concise and the lines regular, so as to avoid too many turning and bending spaces that cause people to escape quickly in panic after a disaster. In addition, green belts can be planted in necessary places. On the one hand, the green belts can be used as an isolation belt for fire methods to prevent the fire from spreading rapidly, and on the other hand, it can also improve the space environment.

\subsubsection{Design of Entrance Node of Underground Space}

As a transforming body and connecting body in the three-dimensional spatial structure of the city, the underground entrance space is used to introduce the flow of people into the underground efficiently and effectively. It can connect the cultural expression of the city's external space with the internal space of urban rail transit, and at the same time provide people with more calmness, and a friendly conversion path.

The urban symbols used in the entrance node of the urban traffic underground space include urban landscape symbols and urban humanistic symbols. These are used for spatial structure, internal configuration, landscape facilities, etc., to increase the sense of hierarchy and rhythm of the underground space and also activate the city's regional image.

\subsubsection{Design of the Square in Front of the Station}

Extending part of the space of the city square to the underground entrance is also a manifestation of the urbanization of the urban complex. This design method helps to form the urban space inside the urban complex. It not only integrates the opening, flow and gathering of the outer urban space, but also maintains the stability and privacy of the underground space. This space also plays the role of organizing traffic and connecting buildings, and has spatial complexities.

\subsubsection{Introduction of Natural Landscape Elements}

The underground space is mostly artificially developed, and the artificial traces are heavy. However, the introduction of natural landscape can be regarded as the connection between the outside world and the underground space, which has the continuity of the space. The fear of space blurs the boundaries of space perception. Natural elements not only refer to natural plants, but also include all things in nature, such as sunlight and natural wind. For example, the glass roof of the Nagahori Underground Street in Osaka, Japan, the light refracted by the glass roof will change with time, forming a changeable and flexible light and shadow art, which not only provides customers with a leisure space, but also provides people with a view of nature (Figure 6). The space of the landscape; the Roppongi hub expands the space capacity through the design of the atrium, relieves the sense of depression in the underground space, and combines the sunken courtyard to maximize the introduction of sunlight and sky into the node, and uses greening and landscape design to blur the ground and underground 
spaces. The boundary naturally guides citizens to transition between the two spaces [5] (Figure 7).

\section{Enlightenment of Tokyo Rail Transit Development Model to Chengdu}

\subsection{Continue to Strengthen the Integrated Construction of Station and City}

With the acceleration of urbanization and the increasingly congested urban traffic,

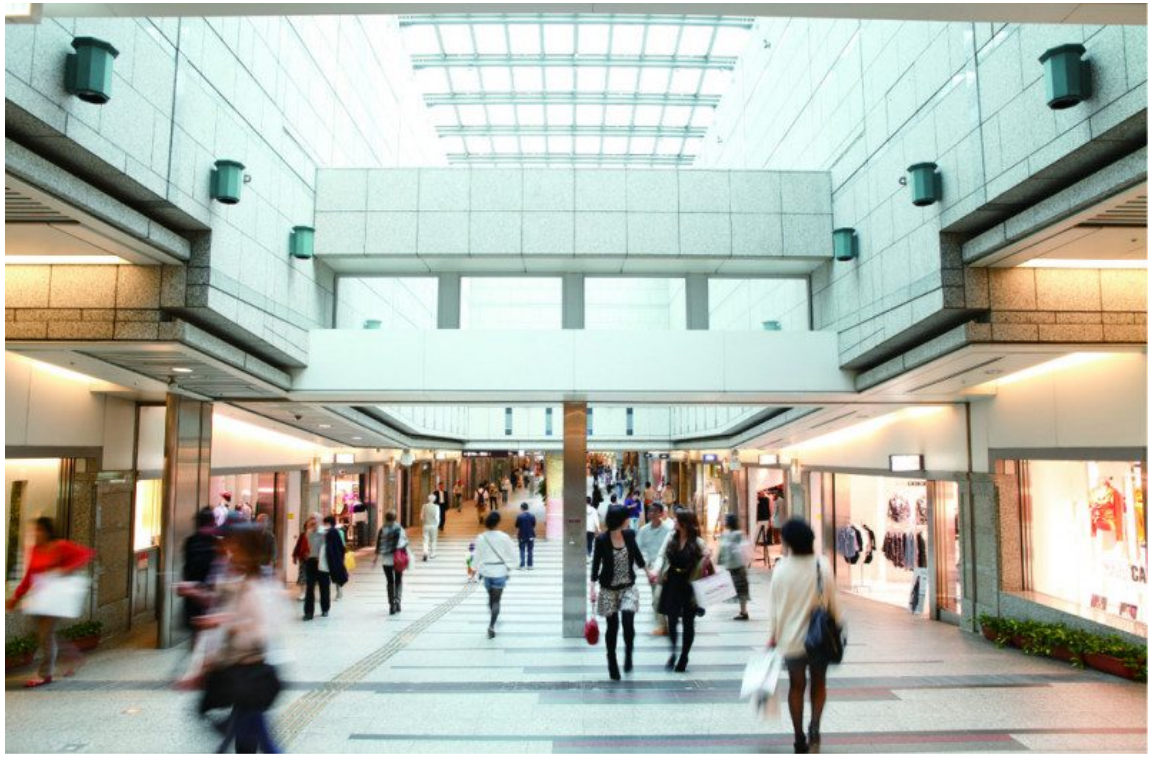

Figure 6. Nagahori, Osaka, Japan (Source: Internet).

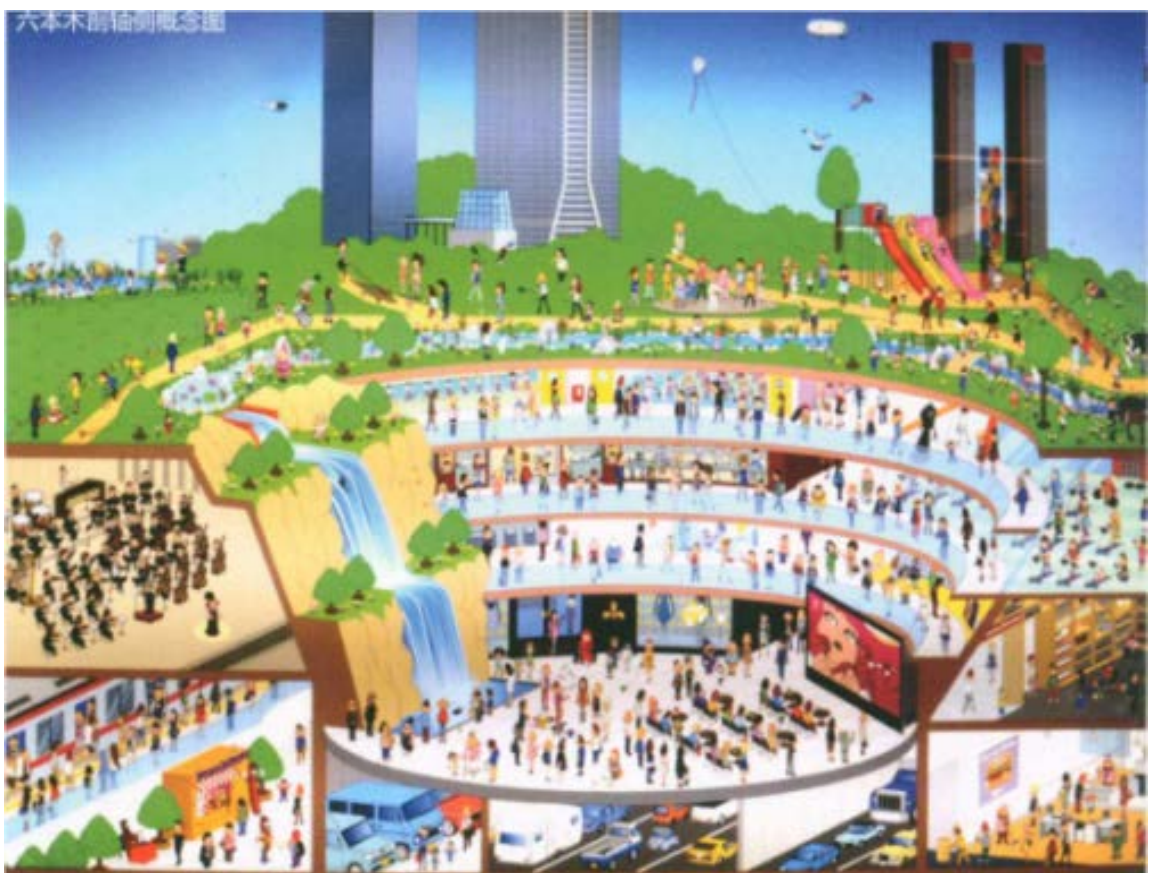

Figure 7. Underground shopping mall Roppongi Hub (Source: reference [4]). 
many cities, including Chengdu, are also actively exploring the development model of urban integrated public transportation. The Chengdu Municipal Government put forward the comprehensive development concept of "integration of stations and cities" in 2018, and the integrated design of 52 stations has been completed. On this basis, Chengdu should continue to be guided by the TOD development model, continue to effectively strengthen the integrated urban construction of station and city integration, coordinate land resources, fully consider the land demand determined by the urban public transportation plan, and do a good job in the control and reservation of station land, Strengthen the protection of comprehensive transportation land, so as to guide the orderly expansion of urban space.

\subsection{Construct and Improve the Rail Transit Network and Optimize the Transportation Supply}

Now Chengdu has opened 7 subway lines: Metro Line 1 (Shengxian Lake-Science City), Line 2 (Longquanyi-Xipu Section), Line 3 (Chengdu Medical CollegeShuangliu West), Line 4 (Xihe-Wansheng), Line 5 (Huagui Road StationShuangliu Huilong Station), Line 10 (Taiping Park-Shuangliu Airport Terminal 2 Section), Metro Line 7 (Circular Line, Second Ring Road, Third Ring Road) The most densely populated area between the rings), Metro Line 9 (Financial City East Station to Huangtianba Station), the overall planned route is an m-shaped network structure. Compared with Tokyo's rail transit, under the background of the urban expansion of Chengdu, its rail transit coverage area and coverage rate need to be improved.

\subsection{Create an Orderly and Efficient Node Transfer System}

The high-efficiency transfer system of rail transit is an inherent requirement for the integrated operation of Zhancheng. Orderly transfer can relieve the pressure on the flow of people during the rush hour and improve the operating efficiency of rail transit. You can refer to Japan's practice of three-dimensional diversion of public transportation hub stations. For example, public vehicles such as taxis and city buses are separated on the first floor of the transportation hub, while social parking is organized and organized to enter the underground, that is, in the middle of the road. Set up entrances and exits for vehicles, and at the same time, the combination of transportation hubs and commercial spaces evacuate and ease the pressure of the flow of people in the area, achieving the effect of threedimensional diversion. Japanese rail transit stations all adopt an integrated transfer method, and pay attention to the connection of subway entrances and exits with various transfer facilities. The subway entrance is an important node for people to enter and exit underground space. The connection relationship with each functional space should be fully considered to achieve a truly efficient transfer system.

\subsection{Optimize the Design of Rail Transit Complex}

The space design of urban rail transit complex is an indispensable link in the 
development of rail transit, and it is also an important factor affecting the transfer system of the entire transit complex. In recent years, under the guidance and support of policies, Chengdu has transformed and built many underground rail transit spaces, and some of its space details have yet to be optimized. Through field observation and data collection, the underground space of rail transit in Chengdu is mainly used to obtain natural light and natural ventilation through the design of open skylights and sunken squares. In the use of artificial lighting equipment, energy-saving lighting systems are adopted, which can be appropriately introduced. Advanced technical equipment includes such as light pipe daylighting system, solar power generation technology, etc.

\section{Conclusion}

The development of rail transit is an inevitable trend of urban construction, and vigorously developing rail transit has become the focus of more and more cities. Therefore, drawing on and developing advanced foreign planning and design ideas will play a vital role in shaping and improving future urban spaces. Through the study of the Tokyo, Japan model of rail transit development, it summarizes the lessons to be learned, and provides a reference point for the future development of rail transit in Chengdu. Although the development of rail transit in our country lags behind some countries, I believe that after continuous learning and practice, we will find a better public transportation development route suitable for our own cities.

\section{Conflicts of Interest}

The author declares no conflicts of interest.

\section{References}

[1] Song, M. (2017) From "Fan Leaf City" to “Compact City”. Ph.D. Dissertation, Southeast University, Nanjing.

[2] Jiang, X.W. (2007) References to Beijing from the Comprehensive Development Model of Tokyo Rail Transit and Land. Master Dissertation, Beijing Jiaotong University, Beijing.

[3] Yang, Z.D. (2014) A Brief Analysis of the Construction Mode of the Combined Development of Rail Transit and Underground Space in Japan. Modern Urban Rail Transit, 93-96+99.

[4] Hong, C.Y. (2018) Research on the Theory and Method of Green Building Design in Underground Public Space. Ph.D. Dissertation, Southwest Jiaotong University, Chengdu.

[5] Wang, J.J. and Zhang, B. (2012) A City Living Underground: Tokyo's Underground Space Utilization and Three-Dimensional Design. World Architecture Guide, 27, 18-23. 